\section{A New Theory of Sunspots} By Dr. E. A. Fath

$A^{\mathrm{T}}$ the meeting of the Royal Astronomical Society

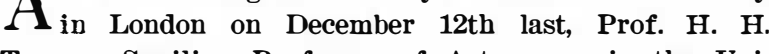
Turner, Savilian Professor of Astronomy in the University of Oxford, presented a new and unique theory of sunspots. The full text of the paper has not yet been received, but Prof. Turner has given the outlines of his theory in the London Times of December 13th. At first glance the theory appears to be quite fantastic, nevertheless its author has been of great service in the modern development of astronomy, and whatever he says deserves a respectful hearing.

The outline of the theory is as follows:

It is well known that at times there are many spots visible on the sun, while at others they are few or entirely wanting. Observations extending over many years have shown that the number of spots varies with some regularity, the average period from maximum to maximum being about eleven years. A few years ago Prof. Schuster found evidence of other periods of about five, eight, and thirteen years. While investigating the problem recently Prof. Turner found certain breaks in the sunspot series at about the dates 1766, 1800, 1833, 1866 , and 1900 . In these years meteor showers know as the Leonids were particularly active. It, therefore appeared that there might be a connection between these meteors and sunspots.

The Leonids themselves are known not to approach very near the sun, and it was therefore impossible to see a direct connection. Some intermediary was therefore required. This intermediary was supposed to be what might be called a subsidiary swarm of meteors which graze the sun at their nearest approach, and also pass so near the orbit of the Leonids that their motion is disturbed by the attraction of the latter when the main swarm of Leonids happens to pass this point.

This subsidiary swarm might have come into existence at a time when the main Leonid swarm was near Saturn. The planet itself probably drew in the larger portion to itself just as the earth draws in shooting stars, but those portions of the swarm which passed through the rings might collide with the components of the latter, and so affect the motion that both meteors and the particles of the rings might be freed from the control of the planet and fall toward the sun. Some would fall directly into the sun and the others would either graze or pass very near the surface of this body.

The dates of the possible encounter of Saturn and the Leonids are given, and, with one exception, these are preceded by a scarcity of sunspots and followed by a marked increase. The last encounter was in 1863. In March of that year a Greenwich observer noted that the inner dusky ring had so increased in brightness that it was nearly as bright as the other rings. This observer therefore may have actually seen the result of the bombardment of Saturn's system by the Leonids. Seven years after this came the great sunspot maximum of 1870. At about this time disturbances in the motion of Saturn in its orbit were noted. If this disturbance was due to the Leonids then the mass of this meteor swarm must be far greater than is usually supposed.

If we can assume that some of these meteors have a large mass, then their fall into the sun must produce a considerable $\mathrm{d}$ is turbance, for they strike with a velocity of about 400 miles per seco disturban per seconif. anifests itself as a sunspot.

We $h$ a ve thus briefly stated the main points of this latest sunspot theory. It leaves many things unexplained, such as the peculiar distribution of the spots in latitude, why the spots in latitude, why the earth does not encounter
huge meteors at times, etc. It may be that the apparent connection of breaks in the sunspot series with the Leonids $\mathrm{m}$ a $\mathrm{y}$ be nothing more than a curious coincidence, and it certainly looks as if the author had gone far afield to find a cause which may reside in the sun itself. Nevertheless, before passing judgment on this unique theory, parts of which Prof. Turner himself says have "an appearance

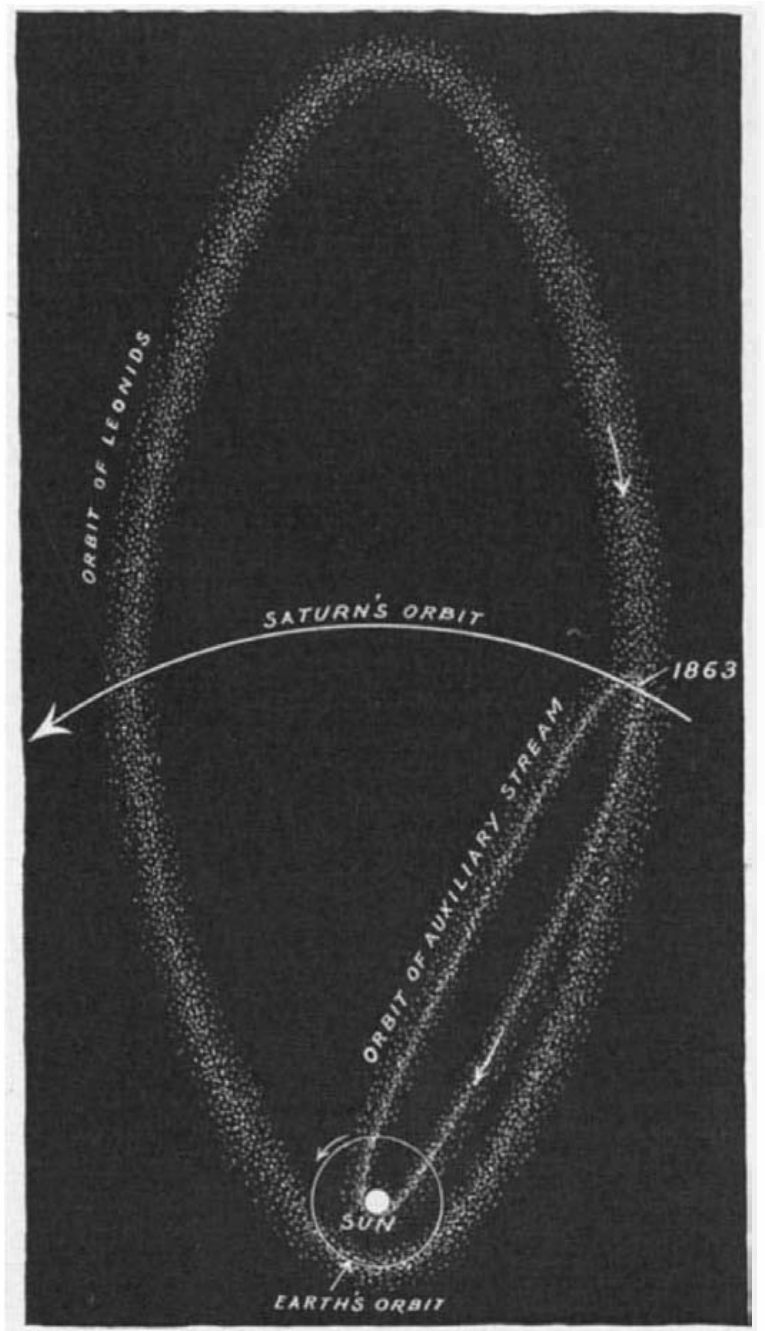

Prof. H. H. Turner suggests that there may be a connec tion between the meteor showers known as the Leonid (the sun-an th mediary found in a subsidiary swarm.

Prof. H. H. Turner's theory of sunspots.

of wild speculation," it will be well to await the publication of the complete paper as presented to the Roya Astronomical Society.

\section{First Magnitude Stars}

By Frederic Campbell, Sc.D., Late President Department of Astronomy, Brooklyn Institute

THE world over and the year through, 8,000 stars are visible to the naked eye. Except the five visible planets of our own solar system, all these are suns. Seen through the best telescopes, their number leaps to 100 million; and photography raises it to one million

million. So says the distinguished scientist, Sir E. Ray Lankester.

To become familiar with such a host is absolutely hopeless. But, just as we may have a dozen or two familiar acquaintances among the billion and a half people on earth, so is it possible to know a few of the most splendid stars. The most learned astronomer, in fact, carries at his belt but a short string of stellar scalps. The first magnitude stars are but twenty in number; and of these only fifteen are ever visible in our northern latitudes. With these fifteen, or even twenty, splendid luminaries there is no excuse for any man's not having acquaintance, as with so many genial friends.

The first magnitude stars are such as appear the brightest to an observer on earth. The term does not mean their actual magnitude, either their mass, volume or inherent brilliancy. It refers only to the amount of light received from each of them at our terrestrial distance, the way they look, not the way they are. Very huge suns might be so distant or so dull as not even to be visible to the naked eye; and a fifth rate orb might be given rank among stars of the first magnitude, simply because it happens to be located comparatively near our own part of the universe.

In the table of first magnitude stars furnished herewith, there should be but little difficulty in committing to memory the names in their order, as we'? as the figures relating to their comparative brilli ncy, their distance and their inherent light. If the southern luminaries, never seen in our northern latitudes, be omitted, the task is materially reduced. To know the facts concerning even these few stars is to know little enough concerning the universe, outside of our own miniature earth. One ought to have the ambition to extend his knowledge that far at the very least.

That we may comprehend the facts set before us in the table, a few remarks need to be made. We have already noted that, of the entire twenty, there are five never seen by us who dwell in the north. Of such immense importance are some of these, that it would be a great loss to omit them from our knowledge because they never show above our horizon. One of these is Canopus, next to Sirius in brilliancy, and $21 / 2$ times as bright as any other star seen in our north. While, as seen from earth, Canopus is second in the list, giving hardly more than half the glory of Sirius, in itself it is first in brilliancy, radiating an effulgence 10,000 times that of our superb sun. Nor are these figures mere estimates, but the result of scientific light measurements, from which the personal equation has been eliminated. Alpha Centauri, too, another southern star, third in the list, is of immense importance, as being the nearest star to earth that we know. Proximity explains its brilliance, for, in itself, it has the splendor of only two such suns as ours.

But, viewing the entire group of first magnitude stars, we see in them an illustration of the long-ago-uttered truth that "one star differeth from another star in glory." This is as true, as viewed from earth, as it is in their inherent light-possession. Expressed in terms of magnitude, they run all the way from -1.6 in Sirius to 0.2 in Capella, 1.1 in Aldebaran and 1.3 in Regulus. Or, in comparisons a mon themselves, they run all the way from Sirius, regarded as 100 , to Altair as 10 and Regulus as 7 , the latter giving only 0.07 as much light as Sirius, yet grouped in the same class. In the matter of inherent brilliancy or absolute light-giving quality, there are immense differences, $r$ un ing from Alpha Centauri, with a light equal to twice that of our sun, to Altair, equal to 12 suns; to Pollux, equal to 125 suns; to Capella, equal to 300 suns; to Antares, 2,000 suns; Rigel, 4,000 suns; and Canopus, already mentioned as

Distance in light years of the nearer first magnitude stars.

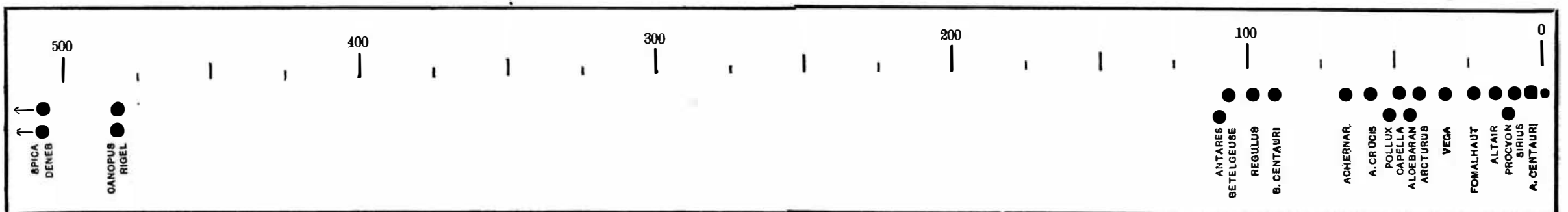

That the brightness of a star is no measure of its distance is shown by this diagram. Canopus stands second only to Sirius in brilliancy, yet it is nearly sixty times as far from us. 